\title{
The global impact of Aspergillus infection on COPD
}

\author{
Emily E. Hammond ${ }^{1 \dagger}$, Charles S. McDonald ${ }^{1 \dagger}$, Jørgen Vestbo ${ }^{2,3}$ and David W. Denning ${ }^{2,4^{*}}$ (D)
}

\begin{abstract}
Background: Advanced chronic obstructive pulmonary disease (COPD) often leads to hospitalisation and invasive aspergillosis (IA) is a serious complication. Aspergillus sensitisation may worsen symptoms in COPD.

Methods: We identified published papers between January 2000 and May 2019 with > 50 subjects and GOLD criteria for grade II, III or IV (FEV1/FVC $<70 \%$ and FEV1 < 80\%) using standardised criteria in multiple countries, to reestimate the prevalence of COPD. Hospitalised COPD patients develop IA in 1.3-3.9\%, based on positive cultures of Aspergillus spp. and radiological findings. Given limited data on per-patient annual hospitalisation rates, we assumed a conservative $10.5 \%$ estimate. Annual IA mortality in COPD was estimated using the literature rates of $43-72 \%$. A separate literature search assessed the impact of Aspergillus sensitisation on severity of COPD (by FEV1).

Results: We re-estimated the global prevalence of COPD GOLD stages II-IV at 552,300,599 people (7.39\% of the population) with 339,206,893 (8.58\%) in Asia, 85,278,783 (8.52\%) in the Americas, 64,298,051 (5.37\%) in Africa, $59,484,329(7.77 \%)$ in Europe and 4,032,543 (10.86\%) in Oceania. An estimated 57,991,563 (10.5\%) people with COPD are admitted to hospital annually and of these 753,073 (1.3\%) - 2,272,322 (3.9\%) develop IA and 540,451-977,082 deaths are predicted annually. Aspergillus sensitisation prevalence in COPD was 13.6\% (7.0-18.3\%) and not related to lower predicted FEV1\% $(P>0.05)$.

Conclusions: The prevalence of COPD is much higher than previously estimated. Overall COPD mortality may be higher than estimated and IA probably contributes to many deaths. Improved rapid diagnosis of IA using culture and non-culture based techniques is required in COPD hospital admissions to reduce mortality.
\end{abstract}

Keywords: Fungal infection, Aspergillus, Emphysema, Survival, Incidence

\section{Background}

Chronic obstructive pulmonary disease (COPD) is the most prevalent non-communicable disease of the lungs. It is both preventable and treatable but usually progressive and irreversible [1] with the majority of deaths from COPD occurring in less-developed countries [2]. An

\footnotetext{
* Correspondence: ddenning@manchester.ac.uk

${ }^{\dagger}$ Emily E. Hammond and Charles S. McDonald are Joint first authors.

${ }^{2}$ Division of Infection, Immunity and Respiratory Medicine, Faculty of Biology, Medicine and Health, University of Manchester and Manchester Academic Health Science Centre, Manchester, UK

${ }^{4}$ National Aspergillosis Centre, Education and Research Centre, Wythenshawe Hospital, Manchester University NHS Foundation Trust, Southmoor Road, Manchester M23 9LT, UK

Full list of author information is available at the end of the article
}

ageing population has led to a relative increase in the burden of COPD morbidity and mortality across the world over recent years which has focused the spotlight on COPD as a significant global health concern [2]. The strongest risk factor for the development of airflow limitation is smoking and indoor exposure to biomass [3]; other factors include family history, genetics including alpha-1antitrypsin deficiency, age, education, tuberculosis, and occupational exposures [4]. Estimates for the prevalence of the disease vary considerably across the globe [5].

Bacteria and viruses are a major cause of COPD exacerbations [6] whereas the role of fungi is less well understood. Most pulmonary fungal infections are caused by members of genus Aspergillus [7]. Aspergilli are

(c) The Author(s). 2020 Open Access This article is licensed under a Creative Commons Attribution 4.0 International License, which permits use, sharing, adaptation, distribution and reproduction in any medium or format, as long as you give appropriate credit to the original author(s) and the source, provide a link to the Creative Commons licence, and indicate if changes were made. The images or other third party material in this article are included in the article's Creative Commons licence, unless indicated otherwise in a credit line to the material. If material is not included in the article's Creative Commons licence and your intended use is not permitted by statutory regulation or exceeds the permitted use, you will need to obtain permission directly from the copyright holder. To view a copy of this licence, visit http://creativecommons.org/licenses/by/4.0/ The Creative Commons Public Domain Dedication waiver (http://creativecommons.org/publicdomain/zero/1.0/) applies to the data made available in this article, unless otherwise stated in a credit line to the data. 
ubiquitous soil-dwelling fungi that have the ability to cause a range of pulmonary conditions including invasive aspergillosis (IA), chronic pulmonary aspergillosis (CPA) including aspergilloma, hypersensitivity pneumonitis, and allergic bronchopulmonary aspergillosis (ABPA) [8]. IA is almost always fatal if not identified and treated early [9]. COPD is one of many underlying risk factors for IA, including neutropenia, liver disease, diabetes mellitus, AIDS, those on immunosuppressive treatment, such as solid and haematopoietic stem cell transplant recipients [9-12]. Prior estimates of the annual global incidence of IA range upwards from 200,000 [9], but difficulties in the precise diagnosis of IA in COPD patients has restrained efforts to include this group in the estimates [10].

One of the aims of this study was to provide global and individual country estimates for the annual number of cases of IA in COPD patients and likely associated mortality. In addition, we wanted to assess whether Aspergillus sensitisation contributes to the severity of COPD as recent publications have noted that COPD patients with allergic sensitisation to Aspergillus fumigatus experience more symptoms and exacerbations [13], and multiple studies have demonstrated a correlation between asthma severity and sensitisation to Aspergillus specifically $[14,15]$.

\section{Methods}

A systematic review of published literature on PubMed was conducted to ascertain country estimates for 1) COPD prevalence (GOLD grade II-IV), 2) COPD annual hospitalisation rates, and 3) annual cases of IA in COPD patients. Countries included in this review were those with populations over one million, as guided by UN 2015 data [16]. The methodology used in this study is summarised in Additional file 1.

\section{COPD prevalence data collation}

Data were initially collected from three large studies: Burden of Obstructive Lung Disease (BOLD), Proyecto Latinoamericano de Investigacion en Obstruccion Pulmonar (PLATINO) and BREATHE to provide estimates on COPD prevalence, $[3,17,18]$. For countries not included in these studies, a structured literature search and review was conducted to identify other individual country studies to ascertain their estimated prevalence of COPD (Additional file 1). For countries where data was either unavailable or unreliable (see exclusion criteria detailed in Additional file 1), COPD prevalence estimates from neighbouring countries (including countries with BOLD and PLATINO sites) were assumed (Additional file 1).

We pritoritized studies where similar methodologies had been applied at multiple sites. Studies that adopted
GOLD criteria were used preferentially; however, a few studies (Rwanda, Estonia and Russia) used lower limit of normal for FEV1/FVC (LLN) to diagnose COPD [19].

Inclusion criteria were:

Studies published between January 2000 and May 2019; Studies with a sample size $>50$ people.

Ssudies with spirometric data were prioritised - use of GOLD criteria to diagnose COPD with spirometry grade II, III or IV (FEV1/FVC $<70 \%$ and FEV1 $<80 \%$ ) or if unavailable then LNN

\section{Exclusion criteria:}

Studies estimating prevalence to be close to or $0 \%$; Studies conducted in specific patient groups; e.g., in acutely unwell patients only.

\section{COPD hospitalisation data collation}

Limited data were available for individual countries on their annual rates of COPD-related hospitalisations. The methodology used, similar to that for COPD prevalence data, is summarised in Additional file 1. As many countries did not have published data for hospitalisations, a conservative $10.5 \%$ estimate was assumed. This was based on the data from studies in Algeria which have estimated COPD hospitalisation rates at $10.5 \%$ [18], not different from the average rate from other studies. The data is therefore more reflective of how many people are admitted, rather than a potentially overestimated figure of how many hospitalisations occur, as it is common for COPD patients to experience more than one exacerbation a year [20].

\section{Sensitisation systematic review}

A systematic review of the prevalence of Aspergillus sensitisation in patients with COPD, and the difference in lung function between sensitised and non-sensitised patients was also conducted. The methodological details using the Strengthening the Reporting of Observational Studies in Epidemiology (STROBE) methods [21] are described in Supplementary data. The data extracted were: 1) Authors, publication year, study design 2) Sample size 3) Population characteristics (age/gender) 4) Study location 5) Method of sensitisation assessment 6) Percentage of sample sensitised to Aspergillus 7) Lung function of sensitised and non-sensitised patients (FEV1 as a percentage of predicted). The flow-chart in Additional file 2: Supplementary Figure S1 describes the study selection.

Weighted averages and weighted standard deviations were computed to compare lung function between sensitised and non-sensitised patients. 


\section{Invasive aspergillosis data collection}

With regards to the incidence of IA in COPD, proportions of the hospitalization estimates from the only four studies are published, from China and Spain, were used to provide an estimated range for each country. The Spanish study estimated 1.3\% of COPD hospitalisations to have IA in the last year of their survey, and the later Chinese study estimated 3.9\% [10, 20]; the earlier Chinese study estimated $1.9-2.7 \%$ [22], in the middle of our range. Their respective mortality rates $(71.7$ and $43.9 \%$ respectively) were also applied to estimate deaths from IA in COPD $[10,20]$ the earlier study from China had an $80 \%$ mortality, but as two patients were excluded from this figure, we elected to use the $71.7 \%$ rate as our upper bound of mortality. The most recent study appeared to have a selective admissions policy and was excluded on these grounds [23].

\section{Results}

Overall, COPD prevalence and associated hospitalisation rates, and data for IA prevalence and associated mortality in COPD populations, were estimated for 157 countries globally. Summary estimates are shown in Table 1 and by country in supplementary Table 1 and show significant variability.

\section{Prevalence}

The global prevalence of COPD GOLD stages II-IV is estimated at $552,300,599$ people $(7.39 \%$ of the population) with $339,206,893$ (8.58\%) in Asia, 85,278,783 (8.52\%) in the Americas, 64,298,051 (5.37\%) in Africa, $59,484,329$ (7.77\%) in Europe and 4,032,543 (10.86\%) in Oceania. China and India account for over 82.7 million
(5.12\% of the Chinese population) and 93.9 million ( $7.10 \%$ of the Indian population) respectively of the global COPD population. Additional file 2 illustrates how the prevalence of COPD varies greatly across the globe. The lowest prevalence of COPD is documented in Peru (1.78\%) and only Morocco, Angola, Cameroon, Chad, Republic of Congo, Democratic Republic of Congo, Equatorial Guinea, Gabon, Colombia and United Arab Emirates have estimated COPD prevalence below 3\% of the population. The highest prevalences were found in South Africa and the USA by the BOLD study, 19.1 and 14.3\% respectively [3], followed by Trinidad and Tobago, Iraq and Denmark (with 14.1, 13.5 and $12.7 \%$ respectively). Some of the lowest results were from countries included in the BREATHE study: the United Arab Emirates and Morocco, with 1.9, and $2.2 \%$ respectively [18]; in Pakistan COPD prevalence was estimated at $2.1 \%$ in the BREATHE study but has since been updated with data from Karachi to $13.8 \%$ [24], throwing these very low rates into question.

\section{Hospitalisation}

An estimated 57,991,563 people with COPD are admitted to hospital annually. There are more admissions than this because the mean number of admissions per year for those admitted is often $>1$, albeit variable. The rates of admission vary by country, but in most studies it is not clear if these are admission numbers or individuals.

\section{Aspergillus sensitisation}

We identified 122 articles via systematic search and an additional three were identified manually (Additional file 2: Supplementary Figure S1). After 27 duplicates were

Table 1 A summary of the data in Table 1, by continent and an overall global estimate of COPD prevalence, hospitalisation rate, IA prevalence in COPD and associated mortality

\begin{tabular}{|c|c|c|c|c|c|c|c|c|}
\hline \multirow[t]{2}{*}{ Region } & \multirow[t]{2}{*}{$\begin{array}{l}\text { Population } \\
\text { size [16] }\end{array}$} & \multirow{2}{*}{$\begin{array}{l}\text { COPD population } \\
\text { GOLD stages II-IV } \\
\text { n (\% of population) }\end{array}$} & \multirow{2}{*}{$\begin{array}{l}\text { COPD annual hospitalisation } \\
\text { rate [18] } \\
10.5 \% \text { of COPD population }\end{array}$} & \multicolumn{2}{|c|}{ IA annual rate $[10,20]$} & \multicolumn{2}{|c|}{ IA mortality rate $[10,20]$} & \multirow{2}{*}{$\begin{array}{l}\text { IA annual } \\
\text { incidence } \\
\text { per } 100,000 \\
\text { population }\end{array}$} \\
\hline & & & & \multicolumn{2}{|c|}{$\begin{array}{l}1.30-3.90 \% \text { of COPD } \\
\text { hospitalisation rate }\end{array}$} & \multicolumn{2}{|c|}{ n (\% of IA cases) } & \\
\hline \multirow[t]{2}{*}{ Africa } & $1,197,415,000$ & $64,298,051(5.37)$ & $6,751,295$ & 87,767 & $1.3 \%$ & 62,929 & $71.7 \%$ & 7.3 \\
\hline & & & & 271,877 & $3.9 \%$ & 115,996 & $43.0 \%$ & 22.7 \\
\hline \multirow[t]{2}{*}{ America } & $1,001,386,000$ & $85,278,783(8.52)$ & $8,954,272$ & 116,406 & $1.3 \%$ & 83,463 & $71.7 \%$ & 11.6 \\
\hline & & & & 349,217 & $3.9 \%$ & 150,163 & $43.0 \%$ & 34.9 \\
\hline \multirow[t]{2}{*}{ Asia } & $4,476,519,000$ & $339,206,893(8.58)$ & $35,616,724$ & 462,894 & $1.3 \%$ & 331,895 & $71.7 \%$ & 10.3 \\
\hline & & & & $1,389,052$ & $3.9 \%$ & 597,292 & $43.0 \%$ & 31.0 \\
\hline \multirow[t]{2}{*}{ Europe } & $765,958,000$ & $59,484,329(7.77)$ & $6,245,855$ & 81,196 & $1.3 \%$ & 58,218 & $71.7 \%$ & 10.6 \\
\hline & & & & 247,744 & $3.9 \%$ & 106,530 & $43.0 \%$ & 32.3 \\
\hline \multirow[t]{2}{*}{ Oceania } & $37,131,000$ & $4,032,543(10.86)$ & 423,417 & 5504 & $1.3 \%$ & 3947 & $71.7 \%$ & 14.8 \\
\hline & & & & 16,513 & $3.9 \%$ & 7101 & $43.0 \%$ & 44.5 \\
\hline \multirow[t]{2}{*}{ Globally } & $7,478,409,000$ & $552,300,599(7.39)$ & $57,991,563$ & 753,073 & $1.3 \%$ & 540,451 & $71.7 \%$ & 10.0 \\
\hline & & & & $2,272,322$ & $3.9 \%$ & 977,082 & $43.0 \%$ & 30.40 \\
\hline
\end{tabular}


removed, the remaining 98 were screened by title and abstract; of these papers, 86 were excluded and 12 full text articles were assessed for eligibility and 5 were deemed suitable for inclusion [25-29]. These five papers describe 1028 patients with COPD, 720 (70\%) male with a mean age of 68.8 years (Table 2). Two of the studies were located in Europe, one in Latin America, one in Southern Asia and one in Eastern Asia.

We estimate that the total global population of COPD patients who are sensitised to Aspergillus is just over 75 million. Serum IgE was the most common method to assess the prevalence of Aspergillus sensitisation. The highest prevalence of sensitisation was in Europe based on studies located in Belgium and the United Kingdom (Table 3). In Belgium, Everaerts et al. reported the highest prevalence of $18.3 \%$ sensitised to Aspergillus [26]. In contrast, Le Pape et al. in Colombia found the lowest prevalence at 7.9\% [29]. The weighted average of sensitisation to Aspergillus across all studies was $13.6 \%$. The maximum proportion of healthy controls $(n=322)$ sensitised to Aspergillus was 4\% (Table 4). The FEV1 was 2.5\% lower in COPD patients sensitised to Aspergillus than non-sensitised patients $(P$-value $=0.57)($ Table 4$)$.

\section{Invasive Aspergillosis}

There are only three studies documenting the incidence of IA in those admitted to hospital [10, 20, 22]. All are based primarily on sputum culture positive for Aspergillus spp. with supportive radiological findings and usually both a failure to respond to antibiotics and a progressive course. One study included Aspergillus antigen and beta 1,3-D-glucan serum biomarkers [22]. These three studies provided the upper and lower bounds of our estimates for IA - 753,073 - 2,272,000 annual cases. As shown in Table 1 , the number affected by continent were variable and vary from a low of 14.8/100,000 in Oceania to a high of 34.9/100,000 in the Americas. Annual incidence vary from a low of 1.77 in Panama to 26.07/100,000 in South Africa and countries neighbouring South Africa
(Botswana, Eswatini, Lesotho and Namibia) (Additional file 2) using the lower estimate of $1.3 \%$ affected. The higher estimate of $3.9 \%$ of COPD hospitalisations affected increases the annual incidence to 5.32 to 78.21 / 100,000 .

There are no data published directly estimating the prevalence of CPA complicating COPD, even though about $33 \%$ of CPA patients have COPD as an underlying diagnosis, $9 \%$ as the primary underlying pulmonary disorder [30]. One recent 12-year retrospective inpatient study from Caruña, Spain which used positive cultures as the enrolment criteria found 68 patients with IA and 7 with CPA [31]. If this ratio pertains in other countries, then CPA complicating COPD would have an inpatient incidence of 76,000 - 272,000. These patients might be included in the overall IA group, as it is likely that this chronic subset of aspergillosis cases was not separated out in the IA COPD studies [10, 20]. Another selective study in China of 36 cases separated them into 25 with IA and 11 with CPA [23]. As most patients with CPA are diagnosed and managed as outpatients, the prevalence of CPA complicating COPD is probably 4-10 times greater than this.

The untreated mortality of invasive aspergillosis is generally thought to be about $100 \%$ but is not carefully documented in COPD patients because of the difficulties in establishing the diagnosis early in the course of disease [22]. We took a conservative view of the likely mortality, by using the rates in the two papers where the diagnosis was actively sought and antifungal treatment usually administered, which is probably not the case in most centres. Applying these mortality rates of $44-72 \%$, 540,451-977,082 deaths from IA in hospitalised COPD patients are predicted annually.

\section{Discussion}

There has not been a global COPD prevalence review conducted based on spirometry and standardised assessments for more than a decade, until this year, published as this was paper was being reviewed [32]. The results

Table 2 Characteristics of included articles on Aspergillus fumigatus sensitisation and COPD populations

\begin{tabular}{|c|c|c|c|c|c|c|c|c|}
\hline \multirow[t]{2}{*}{ Author, year } & \multirow[t]{2}{*}{ Study Location } & \multirow[t]{2}{*}{ Study design } & \multirow{2}{*}{$\begin{array}{l}\text { Mean } \\
\text { age, } \\
\text { years }\end{array}$} & \multicolumn{2}{|c|}{ Gender } & \multicolumn{2}{|c|}{ Population } & \multirow[t]{2}{*}{ Assessment of sensitisation } \\
\hline & & & & Male & Female & Control & COPD & \\
\hline Jin et al, 2014 [25] & Beijing, China & Cross-sectional & 77 & 174 & 99 & 150 & 273 & Plasma IgE analysis \\
\hline $\begin{array}{l}\text { Everaerts et al, } 2017 \\
\text { [26] }\end{array}$ & Leuven, Belgium & Cross-sectional & 67 & 215 & 85 & 50 & 300 & Plasma IgE analysis \\
\hline Agarwal et al, 2010 [27] & Chandigarh, India & $\begin{array}{l}\text { Prospective case- } \\
\text { control }\end{array}$ & 57 & 179 & 21 & 100 & 200 & Skin prick test \\
\hline Bafadhel et al, 2014 [28] & Leicester, UK & longitudinal study & 69 & 89 & 39 & 22 & 128 & $\begin{array}{l}\text { Skin prick test and Plasma lgE } \\
\text { analysis }\end{array}$ \\
\hline Le Pape et al, 2018 [29] & $\begin{array}{l}\text { Bogotá, } \\
\text { Colombia }\end{array}$ & Cross-sectional & 74 & 63 & 64 & - & 127 & Plasma IgE analysis \\
\hline
\end{tabular}


Table 3 Prevalence of Aspergillus sensitisation in patients with COPD.

\begin{tabular}{llll}
\hline Location, author, year & \multicolumn{2}{l}{$\begin{array}{l}\text { Sensitised to } \\
\text { Aspergillus, \% }\end{array}$} & $\begin{array}{l}\text { Number } \\
\text { of patients }\end{array}$ \\
\cline { 2 - 3 } & Control & COPD & \\
\hline China, Jin et al, 2014 [25] & - & 15.0 & 273 \\
Belgium, Everaerts et al, 2017 [26] & 4.0 & 18.3 & 300 \\
India, Agarwal et al, 2010 [27] & 0.0 & 8.5 & 200 \\
United Kingdom, Bafadhel et al, 2014 [28] & - & 13.0 & 128 \\
Colombia, Le Pape et al, 2018 [29] & - & 7.9 & 127 \\
Weighted average: & 2.4 & 13.6 & Total: 1028 \\
\hline
\end{tabular}

from our review of the global data estimate there to be $551,792,354$ individuals suffering with COPD, the majority of whom are classed as GOLD moderate to severe. Given that the most recent global estimate for COPD prevalence was 251 million [33], now up to 300 million according to the Global Burden of Disease consortium [32], our estimate is much higher even excluding countries with populations under 1 million and excluding GOLD stage I data. Our estimate is dwarfed by another recent systematic review and meta-analysis based on 60 papers and 128,000 patients - a global prevalence of 12.1\% (approximately 909 million) [34]. These much higher prevalence figures are not surprising, with underdiagnosis of COPD being one of the major issues facing the management of the disease. During the EPI-SCAN study, Miravitlles et al. found $73 \%$ of the patients in their trial with non-reversible airflow obstruction characteristic of COPD did not have a diagnosis before the study [35]. Furthermore, it has been found that this underdiagnosis appears to affect women disproportionately [36]. In order to minimise the effect of under-diagnosis in our estimate we only used internationally accepted spirometry criteria to define COPD, with the exception of a small number of studies using alternative justified methodology. In contrast, our estimate for the global prevalence of COPD at $8.3 \%$ is lower than the estimate

Table 4 Comparison of FEV1 between sensitised and nonsensitised patients with COPD 7.0-18.3\% (weighted mean 13.6\%

\begin{tabular}{llll}
\hline Author, year & \multicolumn{2}{l}{ FEV1 \% of predicted } & $\begin{array}{l}\text { Number } \\
\text { of patients }\end{array}$ \\
\cline { 2 - 3 } & Sensitised & Non-sensitised & \\
\hline Jin et al, 2014 [25] & 37 & 41 & 142 \\
Everaerts et al, 2017 [26] & 41 & 43 & 300 \\
Agarwal et al, 2010 [27] & 52.9 & 48.9 & 200 \\
Bafadhel, 2014 [28] & 39 & 51 & 128 \\
$\begin{array}{l}\text { Weighted average } \\
\text { (weighted SD) }\end{array}$ & $43.0(7.0)$ & $45.5(4.6)$ & \\
\hline
\end{tabular}

of $8.9 \%$ made in a review by Halbert et al [37]; this is the only review of global COPD prevalence defined by spirometry we could identify. Over $20 \%$ of the studies included by Halbert et al. in their analysis defined COPD as GOLD stage I or above (FEV1/FVC $<0.7$ ), this could contribute to their higher estimate of prevalence as we only included GOLD stage II or above in our analysis. We chose to exclude GOLD stage I from our review because using this to define COPD has been shown to over-diagnose elderly patients [38], and there is greater realisation of the variable size of lungs as a result of childhood pollution and other factors interfering with normal lung development [39]. We opted to select studies defining COPD by GOLD stage II-IV over LLN criteria to increase consistency within our review, because the GOLD criteria are more commonly used to define COPD in epidemiology studies, and because using LLN criteria may underdiagnose patients [40].

There are some limitations to the methodology used for calculating prevalence. We did use whole population prevalence, rather than restricting to only those over 40 years of age, as increasing reports of young people with COPD are emerging. As countries with populations less than 1 million were not included, the true total COPD prevalence globally may be slightly higher. The exclusion of GOLD stage I COPD under-estimates mild COPD. We adopted this stance partly because many patients with GOLD stage I COPD (FEV1 $\geq 80 \%$ ) are undiagnosed [41] and country data are probably unreliable and under-representative. A good example is data from United Arab Emirates, Pakistan and Morocco, with COPD prevalence of $1.9 \%, 2.1 \%$ and $2.2 \%$, respectively [42]. Given the high rates of smoking in these countries [43], we do not consider these prevalence rates to be reflective of their true COPD prevalence. The prevalence used for over half the countries included in our review was based on assumptions taken from other countries. Further data are required, in particular for Sub-Saharan Africa and certain parts of Europe, also recognized by Halbert et al [37]. A more recent systematic review analysing the burden of COPD in Latin America and the Caribbean was only able to identify one paper in the Caribbean region [44].

Biomass fuels and mining are also causative factors in the onset of reduced lung function and progression of COPD $[45,46]$. A study in Eastern Europe highlighted a past medical history of pneumonia or tuberculosis (TB) as additional risk factors for the development of COPD [47]. In areas where TB is more prevalent, such as India (which accounted for $24 \%$ of total TB cases in 2016 [48]) and South Africa, this could be a causative factor for a higher prevalence of COPD. In 2019, 62\% of cases of TB were in South-East Asia and the Western Pacific [48], 
Table 5 Hospitalisation data by country collated from our systematic literature review. The BREATHE study [18, 42] and Foo et al [59] documented the incidence of hospitalisations per patient, whereas other studies $[45,63]$ do not clarify whether the figures reflect total number of hospitalisations annually (a patient can have multiple exacerbations a year requiring admission, dependent on their stage of disease), or per patient. A conservative estimate of $10.5 \%$, based on the BREATHE study's figure for Algeria was used to calculate average hospitalisation rates for all countries

\begin{tabular}{|c|c|c|c|c|}
\hline & Country & Study & Study size & COPD annual hospitalisation rate \\
\hline \multirow[t]{5}{*}{ Africa } & Northern Africa & & & \\
\hline & Algeria & BREATHE study, $2012[18,42]$ & 3,675 & $10.50 \%$ \\
\hline & Egypt & BREATHE study, $2012[18,42]$ & 9,804 & $20.30 \%$ \\
\hline & Morocco & BREATHE study, $2012[18,42]$ & 3,983 & $13.00 \%$ \\
\hline & Tunisia & BREATHE study, $2012[18,42]$ & 1,952 & $11.30 \%$ \\
\hline \multirow[t]{7}{*}{ Americas } & Latin American and the Caribbean & & & \\
\hline & Brazil & Foo et al, 2016 [59] & 300 & $20.00 \%$ \\
\hline & Colombia & Alvarez-Moreno et al, 2018 [60] & Population & $13.99 \%$ \\
\hline & Mexico & Foo et al, 2016 [59] & 328 & $14.00 \%$ \\
\hline & Trinidad and Tobago & Gugnani and Denning, 2015 [61] & Population & $13.00 \%$ \\
\hline & Northern America & & & \\
\hline & United States of America & Foo et al, 2016 [59] & 1,001 & $12.00 \%$ \\
\hline \multirow[t]{15}{*}{ Asia } & Eastern Asia & & & \\
\hline & China & Zhu et al, 2018 [45] & 155,777 & $20.87 \%$ \\
\hline & Japan & Foo et al, 2016 [59] & 300 & $3.00 \%$ \\
\hline & Korea (Republic of) & Foo et al, 2016 [59] & 300 & $5.00 \%$ \\
\hline & South-Eastern Asia & & & \\
\hline & Thailand & Chayakulkeeree et al, 2017 [62] & 731,450 & $7.00 \%$ \\
\hline & Southern Asia & & & \\
\hline & Pakistan & BREATHE study, $2012[18,42]$ & 3,654 & $13.00 \%$ \\
\hline & Western Asia & & & \\
\hline & Jordan & BREATHE study, $2012[18,42]$ & 3,596 & $20.70 \%$ \\
\hline & Lebanon & BREATHE study, $2012[18,42]$ & 3,417 & $28.80 \%$ \\
\hline & Saudi Arabia & BREATHE study, $2012[18,42]$ & 9,675 & $22.20 \%$ \\
\hline & Syrian Arab Republic & BREATHE study, $2012[18,42]$ & 3,402 & $21.90 \%$ \\
\hline & Turkey & BREATHE study, $2012[18,42]$ & 14,911 & $19.30 \%$ \\
\hline & United Arab Emirates & BREATHE study, $2012[18,42]$ & 3,482 & $40.70 \%$ \\
\hline \multirow[t]{13}{*}{ Europe } & Eastern Europe & & & \\
\hline & Romania & Mares et al, 2018 [63] & Population & $22.07 \%$ \\
\hline & Russian Federation & Foo et al, 2016 [59] & 301 & $14.00 \%$ \\
\hline & Northern Europe & & & \\
\hline & United Kingdom and N. Ireland & Foo et al, 2016 [59] & 305 & $15.00 \%$ \\
\hline & Southern Europe & & & \\
\hline & Greece & Gamaletsou et al, 2016 [64] & Population & $7.70 \%$ \\
\hline & Italy & Foo et al, 2016 [59] & 302 & $6.00 \%$ \\
\hline & Spain & Foo et al, 2016 [59] & 303 & $16.00 \%$ \\
\hline & Western Europe & & & \\
\hline & France & Foo et al, 2016 [59] & 300 & $8.00 \%$ \\
\hline & Germany & Foo et al, 2016 [59] & 300 & $9.00 \%$ \\
\hline & Netherlands & Foo et al, 2016 [59] & 303 & $7.00 \%$ \\
\hline
\end{tabular}


which could explain why the results of this study showed high prevalence of COPD in Asia.

Life expectancy is another factor influencing COPD prevalence; countries with lower life expectancies, such as in Sub-Saharan Africa [49], may have a lower prevalence for moderate to severe COPD due to patients dying from other causes before their COPD can progress. There is limited published data available for the majority of Sub-Saharan Africa and so it is difficult to highlight a specific country from the results to illustrate this. Further studies are needed to ascertain the prevalence of COPD in this region.

The BREATHE study was one of the large studies used initially to provide COPD prevalence estimates for a number of countries in the Middle East and North Africa. The study used an epidemiological survey to diagnose COPD and estimate its prevalence $[18,42]$, therefore, unlike the rest of the data included in this review, spirometry was not used as a diagnostic tool. The BREATHE study was included given that it provided data for countries in regions where limited data was available, and could therefore also be used as estimates for other neighbouring countries in Africa and the Middle East. The study provides a sound rationale for using the epidemiological survey that COPD is often not diagnosed until it is clinically apparent and moderately advanced, however patients may still be symptomatic, with an impact on quality of life [11]. Reviewing the prevalence figures, they appear to be very conservative, such as a $1.90 \%$ prevalence for the United Arab Emirates, where tobacco use is self-reported in $36 \%$ of the male population [50].

\section{COPD hospitalisation rates}

Due to wide range of data available for individual country hospitalisation rates for COPD (Table 5), we applied a conservative figure of $10.5 \%$ to each country's COPD figures. In our systematic review, we sought per patient annual rates, rather than the total number of annual COPD hospitalisations that are probably higher. The BREATHE study [18, 42] and Foo et al [59] documented the incidence of hospitalisations per patient, whereas studies conducted by Zhu et al [45] and Mares et al [63] are unclear whether the figures reflect total number of hospitalisations annually or per patient. We did not interrogate individual country databases. There are several country-specific factors that could feed into hospitalisation rates, including access to healthcare and differences in healthcare systems. In developing countries where resource may be limited or a cost is involved in seeing a healthcare professional, hospitalisation rates will be lower than industrialised countries [48]. Our conservative estimate of over 57 million people admitted to hospital comprises $14 \%$ of the global number of 421 million hospital admissions in 2009 [51] and is about 6 times more than influenza as estimated in 2017 [52], likely with some duplication. However, there remains much uncertainty about this number of hospitalisations.

\section{Aspergillus sensitisation}

Early indicators were that Aspergillus sensitization would reduce FEV1 and therefore impact on the severity of COPD, but overall this was not the case - only $2.5 \%$ lower and not statistically significant. This contrasts with asthma in adults [53], cystic fibrosis [54] and tuberculosis [55], where Aspergillus sensitisation is associated with worse lung function, for mechanistic reasons that are not well exemplified. The subgroup of COPD patients with asthma needs more study however, as antifungal therapy of severe asthma with fungal sensitisation improves symptoms [56]. Further, COPD patients with fungal sensitisation exhibit greater eosinophilia, which could alter therapy [57]. A recent paper links fungal, and especially Aspergillus, sensitisation to increased exacerbations of COPD [65].

\section{Invasive aspergillosis}

Due to the limited published data for IA in the context of COPD, it is challenging to provide an accurate estimate on an individual country basis. Assumptions of IA rates in COPD have been made based on the large studies from China and Spain [10, 20]; however, several factors can influence these figures, including the severity of COPD. Studies have shown that infection is more common in the more severe stages, III and IV, of COPD [10, $44,58]$. Therefore, the rates of IA will be influenced by the proportion of the patients with more severe COPD, probably by corticosteroid prescribing practice and possibly by exposure to Aspergillus. More studies focused specifically on cases of IA in specific country populations are necessary to build a more accurate picture of the risk associated with COPD and invasive fungal disease. The figures from Spain and China do, however, provide an indication of the overall potential risk of those with COPD and the associated likelihood of contracting a fungal infection. From these three studies, we have estimated the global number of cases of IA in COPD populations to be between $760,017-2,272,322$. This is substantially higher than the previously estimated 200,000 cases of IA per year (of all causes, not solely COPD) [9]. These data, which need confirmation, are important to raise awareness in healthcare systems to include invasive fungal infection as a differential diagnosis in COPD patients presenting with an exacerbation, and to exclude/treat appropriately and quickly and thence lower attributable mortality, which is otherwise high $[9$, $10,20]$. The high number if IA cases in COPD may surprise clinicians but should perhaps underscore the need to look for more than the usual infection culprits (i.e. $H$. influenzae) in COPD exacerbations. Often, more intense 
infection diagnostics and imaging beyond an ordinary chest $\mathrm{x}$-ray will be required, although neither serum assays for galactomannan (Aspergillus antigen) nor beta 1 , 3 -D-glucan are satisfactory with positive predictive values of $21.1 \%$ and $8.7 \%$ respectively although high negative predictive values of $>99.5 \%$ [22]. Aspergillus antibody detection in serum and molecular and culture testing of respiratory samples may be optimal, but needs thorough evaluation [7].

The range of mortality associated with IA in COPD populations was calculated to be between $544,932-976,187$ deaths annually. Deaths from COPD ranked 10th among all causes of death in 2015, 4th among countries with a middle Socio-Demographic Index, with an estimated 3, 188,000 deaths [58]. Lower respiratory infections were thought to have lead to $2,376,700$ deaths. Our estimate of deaths from IA are remarkably high given these estimates and need validation with additional epidemiology studies. In one sense they are conservative, as they assume the diagnosis of IA is made and treatment given. Middleincome countries are hit particularly hard by COPD deaths; therefore improved epidemiological data in these areas would facilitate governments and healthcare organisations making better informed decisions to better reduce premature deaths.

\section{Conclusion}

In conclusion, the global burden of COPD is high, and although variable, likely to be a much larger global health problem than previously realised. Our study highlights the need for healthcare professionals to be aware of the possible risk of IA in their patients, and associated mortality, to identify and treat patients sooner, lowering mortality. We hope that this report will encourage further research into COPD epidemiology and the relationship between Aspergillus infection and COPD.

\section{Supplementary information}

Supplementary information accompanies this paper at https://doi.org/10. 1186/s12890-020-01259-8.

Additional file 1. The methodology tree describing the structured literature searches and process of data collation for country COPD prevalence estimates and COPD hospitalisation rates.

Additional file 2: Supplementary Figure S1. Literature searching for articles on Aspergillus sensitisation and COPD. Supplementary Table $\mathbf{1 .}$ Population in thousands; COPD prevalence (GOLD stages II-IV) estimates; number of COPD hospitalisations annually by country; IA prevalence in COPD populations and associated mortality risk. Two data values are given for IA and their respective mortalities, to create a range of minimum and maximum prevalence and mortality with the Spain $(1.3 \%$ prevalence and respective mortality of $71.7 \%$ ) and China (3.9\% and respective mortality of $43.0 \%$ ). Mortality is calculated from the figures provided by Spain $(71.7 \%$, from the $1.3 \%$ prevalence figure calculated) and China studies ( $43.0 \%$, from the $3.9 \%$ prevalence figure calculated).
Additional file 3. Estimated global incidence of invasive aspergillosis per 100,000 population, assuming the lower estimate of $1.3 \%$ of hospitalised COPD patients. Countries with populations $<1$ million were not estimated and are in white.

\begin{abstract}
Abbreviations
ABPA: Allergic bronchopulmonary aspergillosis; COPD: Chronic obstructive pulmonary disease; CPA: Chronic pulmonary aspergillosis; FEV1: Forced expiratory volume in $1 \mathrm{~s}$; FVC: Forced vital capacity; GOLD: Global Initiative for Chronic Obstructive Lung Disease; IA: Invasive aspergillosis; LLN: Lower limit of normal; PLATINO: Proyecto Latinoamericano de Investigacion en Obstruccion Pulmonar; STROBE: Strengthening the Reporting of Observational Studies in Epidemiology; UN: United Nations; USA: United States of America
\end{abstract}

\section{Acknowledgements}

Not applicable.

\section{Authors' contributions}

The study plan was conceived by DWD who acts as guarantor of the work. $\mathrm{JV}$ and DWD guided the search strategies and study inclusion and exclusion criteria. EM and CMCD undertook the literature reviews, extracted all the data and prepared the estimates. All authors contributed to writing the report. CMcD plotted the map in Additional file 3. The author(s) read and approved the final manuscript.

\section{Funding}

This study received no external funding. JV and DD are supported by the NIHR Manchester BRC.

\section{Availability of data and materials}

All data generated or analysed during this study are included in this published article [and its supplementary information files].

\section{Ethics approval and consent to participate}

Not applicable.

\section{Consent for publication}

Not applicable.

\section{Competing interests}

$\mathrm{EEH}$ and $\mathrm{CMCD}$ have no competing interests. JV reports personal fees from GlaxoSmithKline, personal fees from Chiesi Pharmaceuticals, personal fees from Boehringer-Ingelheim, personal fees from Novartis, personal fees from AstraZeneca, grants from Boehringer-Ingelheim, outside the submitted work. DWD reports that he and family hold Founder shares in F2G Ltd., a University of Manchester spin-out antifungal discovery company. He acts or has recently acted as a consultant to Scynexis, Pulmatrix, Pulmocide, Zambon, iCo Therapeutics, Mayne Pharma, Roivant, Biosergen, and Fujifilm. In the last 3 years, he has been paid for talks on behalf of Dynamiker, Hikma, Gilead, Merck, Mylan and Pfizer. He is a longstanding member of the Infectious Disease Society of America Aspergillosis Guidelines group, the European Society for Clinical Microbiology and Infectious Diseases Aspergillosis Guidelines group.

\section{Author details}

${ }^{1}$ School of Medicine, University of Manchester, Manchester, UK. ${ }^{2}$ Division of Infection, Immunity and Respiratory Medicine, Faculty of Biology, Medicine and Health, University of Manchester and Manchester Academic Health Science Centre, Manchester, UK. ${ }^{3}$ North West Lung Centre, Wythenshawe Hospital, Manchester University NHS Foundation Trust, Manchester, UK. ${ }^{4}$ National Aspergillosis Centre, Education and Research Centre, Wythenshawe Hospital, Manchester University NHS Foundation Trust, Southmoor Road, Manchester M23 9LT, UK. 
Received: 15 July 2020 Accepted: 5 August 2020

\section{Published online: 11 September 2020}

\section{References}

1. Barnes PJ, Burney PGJ, Silverman EK, et al. Chronic obstructive pulmonary disease. Nat Rev Dis Prim. 2015;1(1):15076. https://doi.org/10.1038/nrdp. 2015.76..

2. Burney PGJ, Patel J, Newson R, et al. Global and regional trends in COPD mortality, 1990-2010. Eur Respir J. 2015;45(5):1239-47. https://doi.org/10. 1183/09031936.00142414..

3. Buist AS, McBurnie MA, Vollmer WM, et al. International variation in the prevalence of COPD (The BOLD Study): a population-based prevalence study. Lancet. 2007;370(9589):741-50. https://doi.org/10.1016/S01406736(07)61377-4..

4. Hooper R, Burney P, Vollmer WM, et al. Risk factors for COPD spirometrically defined from the lower limit of normal in the BOLD project. Eur Respir J. 2012;39(6):1343-53. https://doi.org/10.1183/09031936.00002711..

5. Mannino DM, Buist AS. Global burden of COPD: risk factors, prevalence, and future trends. Lancet. 2007;370(9589):765-73. https://doi.org/10.1016/S01406736(07)61380-4..

6. Sethi S, Murphy TF. Infection in the pathogenesis and course of chronic obstructive pulmonary disease. N Engl J Med. 2008;359(22):2355-65. https:// doi.org/10.1056/nejmra0800353..

7. Bulpa P, Dive A, Sibille Y. Invasive pulmonary aspergillosis in patients with chronic obstructive pulmonary disease. Eur Respir J. 2007;30(4):782-800. https://doi.org/10.1183/09031936.00062206..

8. Al-Alawi A, Ryan CF, Flint JD, et al. Aspergillus-related lung disease. Can Respir J. 2005;12(7):377-87. https://doi.org/10.1155/2005/759070..

9. Brown $\mathrm{G}$, Denning $D$, Gow N, et al. Hidden killers: human fungal infections. Sci Transl Med. 2012;4(165):165rv13.

10. Guinea J, Torres-Narbona M, Gijón P, et al. Pulmonary aspergillosis in patients with chronic obstructive pulmonary disease: incidence, risk factors, and outcome. Clin Microbiol Infect. 2010;16(7):870-7.

11. Chakrabarti A, Chatterjee S, Das A, et al. Invasive aspergillosis in developing countries. Med Mycol. 2011;49(S1):S35-47.

12. Riera F, Caeiro J, Denning D. Burden of serious fungal infections in Argentina. J Fungi. 2018:4(2):51.

13. Jamieson DB, Matsui EC, Belli A, et al. Effects of allergic phenotype on respiratory symptoms and exacerbations in patients with chronic obstructive pulmonary disease. Am J Respir Crit Care Med. 2013;188(2):187-92. https://doi. org/10.1164/rccm.201211-21030C.

14. Fairs A, Agbetile J, Hargadon B, et al. IgE sensitization to Aspergillus fumigatus is associated with reduced lung function in asthma. Am J Respir Crit Care Med. 2010;182(11):1362-8. https://doi.org/10.1164/rccm.20100100870C..

15. Chopra V, Jain H, Goel AD, et al. Correlation of aspergillus skin hypersensitivity with the duration and severity of asthma. Monaldi Arch Chest Dis. 2017:87(3). https://doi.org/10.4081/monaldi.2017.826.

16. United Nations Statistics Division. UN data. http://data.un.org/. Accessed 3 June 2019.

17. Menezes AMB, Perez-Padilla R, Jardim JB, et al. Chronic obstructive pulmonary disease in five Latin American cities (the PLATINO study): a prevalence study. Lancet. 2005;366(9500):1875-81. https://doi.org/10.1016/ S0140-6736(05)67632-5..

18. Polatli M, Ben Kheder A, Wali S, et al. Chronic obstructive pulmonary disease and associated healthcare resource consumption in the Middle East and North Africa: The BREATHE study. Respir Med. 2012;106:S75-85. https://doi. org/10.1016/S0954-6111(12)70016-1.

19. Mohamed Hoesein F, Zanen P, Sachs A, et al. Spirometric thresholds for diagnosing COPD: 0.70 or LLN, Pre- or Post-dilator values? COPD. 2012;9(4):33843.

20. Xu H, Li L, Huang W, et al. Invasive pulmonary aspergillosis in patients with chronic obstructive pulmonary disease: a case control study from China. Clin Microbiol Infect. 2012;18(4):403-8..

21. von Elm E, Altman DG, Egger M, et al. The Strengthening the Reporting of Observational Studies in Epidemiology (STROBE) statement: guidelines for reporting observational studies. J Clin Epidemiol. 2008;61(4):344-9. https:// doi.org/10.1016/J.JCLINEPI.2007.11.008..

22. Gao X, Chen L, Hu G, et al. Invasive pulmonary aspergillosis in acute exacerbation of chronic obstructive pulmonary disease and the diagnostic value of combined serological tests. Ann Saudi Med. 2010;30(3):193-7..
23. He Q, Li H, Rui Y, et al. Pentraxin 3 gene polymorphisms and pulmonary aspergillosis in chronic obstructive pulmonary disease patients. Clin Infect Dis. 2018;66(2):261-7..

24. Arsalan A, Shad Z, Sabah A, et al. Prevalence and therapy of chronic obstructive pulmonary disease in Karachi. Int J Pharm Teach Pract. 2012;5(1):867-904..

25. Jin J, Liu X, Sun Y. The prevalence of increased serum IgE and Aspergillus sensitization in patients with COPD and their association with symptoms and lung function. Respir Res. 2014;15:130..

26. Everaerts S, Lagrou K, Dubbeldam A, et al. Sensitization to Aspergillus fumigatus as a risk factor for bronchiectasis in COPD. Int J Chron Obstruct Pulmon Dis. 2017;12:2629. https://doi.org/10.2147/COPD.S141695..

27. Agarwal R, Hazarika B, Gupta D, et al. Aspergillus hypersensitivity in patients with chronic obstructive pulmonary disease: COPD as a risk factor for ABPA? Med Mycol. 2010;48(7):988-94. https://doi.org/10.3109/13693781003743148.

28. Bafadhel M, McKenna S, Agbetile J, et al. Aspergillus fumigatus during stable state and exacerbations of COPD. Eur Respir J. 2014;43(1):64-71. https://doi. org/10.1183/09031936.00162912..

29. Le Pape P, Alvarez Moreno C, Canas A, et al. Aspergillus in patients with chronic lung disease in Colombia: The prevalence of increases serum lgE, Aspergillus sensitization and colonization. Med Mycol. 2018;56(2):116..

30. Smith N, Denning DW. Underlying pulmonary disease frequency in patients with chronic pulmonary aspergillosis. Eur Resp J. 2011;37:865-72..

31. Molinos-Castro S, Pesqueira-Fontán PM, Rodríguez-Fernández S, et al. Clinical factors associated with pulmonary aspergillosis in patients with chronic obstructive pulmonary disease. Enferm Infecc Microbiol Clin. 2020; 38(1):4-10. https://doi.org/10.1016/j.eimc.2019.06.007 Epub 2019 Aug 9. English, Spanish. PubMed PMID: $31405617 .$.

32. Soriano JB, Kendrick PJ, Paulson KR, et al. Prevalence and attributable health burden of chronic respiratory diseases, 1990-2017: a systematic analysis for the Global Burden of Disease Study 2017. Lancet Respir Med. 2020;8(6):585-96.

33. World Health Organisation. Chronic obstructive pulmonary disease (COPD). 2019. [online] Available at: https://www.who.int/news-room/fact-sheets/ detail/chronic-obstructive-pulmonary-disease-(copd). Accessed 7 June 2019.

34. Varmaghani M, Dehghani M, Heidari E, et al. Global prevalence of chronic obstructive pulmonary disease: systematic review and meta-analysis. East Mediterr Health J. 2019:25(1):47-57 https://doi.org/10.26719/emhj.18.014..

35. Miravitlles M, Murio C, Tirado-Conde G, et al. Geographic differences in clinical characteristics and management of COPD: the EPOCA study. Int J Chron Obstruct Pulmon Dis. 2008;3:803-14.

36. Ancochea J, Miravitlles M, García-Río F, et al. Underdiagnosis of chronic obstructive pulmonary disease in women: quantification of the problem, determinants and proposed actions. Arch Bronconeumol (English Ed.). 2013; 49(6):223-9..

37. Halbert RJ, Natoli JL, Gano A, et al. Global burden of COPD: systematic review and meta-analysis. Eur Respir J. 2006;28(3):523-32. https://doi.org/10. 1183/09031936.06.00124605.

38. Hardie JA, Buist AS, Vollmer WM, et al. Risk of over-diagnosis of COPD in asymptomatic elderly never-smokers. Eur Respir J. 2002;20(5):1117-22. https://doi.org/10.1183/09031936.02.00023202..

39. Lange $P$, Celli $B$, Agustí $A$, et al. Lung-function trajectories leading to chronic obstructive pulmonary disease. N Engl J Med. 2015;373:111-22..

40. Güder G, Brenner S, Angermann CE, et al. GOLD or lower limit of normal definition? A comparison with expert-based diagnosis of chronic obstructive pulmonary disease in a prospective cohort-study. Respir Res. 2012;13(1):13. https://doi.org/10.1186/1465-9921-13-13..

41. Lindberg A, Bjerg-Bäcklund A, Rönmark E, et al. Prevalence and underdiagnosis of COPD by disease severity and the attributable fraction of smoking. Respir Med. 2006;100(2):264-72.

42. Tageldin M, Nafti S, Khan J, et al. Distribution of COPD-related symptoms in the Middle East and North Africa: Results of the BREATHE study. Respi Med. 2012;106:S25-32..

43. Khattab A, Javaid A, Iraqi G, et al. Smoking habits in the Middle East and North Africa: Results of the BREATHE study. Respir Med. 2012;106:S16-24. https://doi.org/10.1016/S0954-6111(12)70011-2..

44. Ciapponi A, Alison L, Agustina M, et al. The epidemiology and burden of COPD in Latin America and the Caribbean: systematic review and metaanalysis. COPD. 2012;11(3):339-50..

45. Zhu B, Wang Y, Ming J, et al. Disease burden of COPD in China: a systematic review. Int J Chron Obstruct Pulmon Dis. 2018;13:1353-64..

46. Santo Tomas L. Emphysema and chronic obstructive pulmonary disease in coal miners. Curr Opin Pulm Med. 2011;17(2):123-5. 
47. Nugmanova D, Feshchenko $Y$, lashyna $L$, et al. The prevalence, burden and risk factors associated with chronic obstructive pulmonary disease in Commonwealth of Independent States (Ukraine, Kazakhstan and Azerbaijan): results of the CORE study. BMC Pulm Med. 2018;18(1):26..

48. WHO Global Tuberculosis Report 2019. https://www.who.int/tb/ publications/global_report/en/. Accessed 6 Dec 2019.

49. UN News. Life expectancy in sub-Saharan Africa is lower now than 30 years ago: UN index. 2019. [online] Available at: https://news.un.org/en/story/2 006/11/199062-life-expectancy-sub-saharan-africa-lower-now-30-years-agoun-index. Accessed 7 June 2019.

50. Al-Houqani M, Leinberger-Jabari A, Al Naeemi A, et al. Patterns of tobacco use in the United Arab Emirates Healthy Future (UAEHFS) pilot study. PLOS ONE. 2018;13(5):e0198119..

51. Jha AK, Larizgoitia I, Audera-Lopez C, et al. The global burden of unsafe medical care: analytic modelling of observational studies. BMJ Qual Saf. 2013;22:809-15.

52. GBD 2017 Influenza Collaborators. Mortality, morbidity, and hospitalisations due to influenza lower respiratory tract infections, 2017: an analysis for the Global Burden of Disease Study 2017. Lancet Respir Med. 2019;7:69-89..

53. Arroyave WD, Rabito FA, Carlson JC, Orleans N. The relationship between a specific IgE level and asthma outcomes: results from the 2005-2006 National Health and Nutrition Examination Survey. J Allergy Clin Immunol Pract. 2013;1:501-8.

54. Baxter CG, Dunn G, Jones AM, et al. Novel immunologic classification of aspergillosis in adult cystic fibrosis. J Allergy Clin Immunol. 2013;132:560-6..

55. Dhooria S, Kumar P, Saikia B, Aggarwal A, Gupta D, Behera D, Chakrabarti A, Agarwal R. Prevalence of Aspergillus sensitisation in pulmonary tuberculosisrelated fibrocavitary disease. Int J Tuberc Lung Dis. 2014;18(7):850-5.

56. Denning DW, O'Driscoll BR, Powell G, et al. Randomized controlled trial of oral antifungal treatment for severe asthma with fungal sensitisation (SAFS), the FAST study. Am J Resp Crit Care Med. 2009;179:11-8.

57. Agarwal K, Gaur SN, Chowdhary A. The role of fungal sensitisation in clinical presentation in patients with chronic obstructive pulmonary disease. Mycoses. 2015;58(9):531-5. https://doi.org/10.1111/myc.12352.

58. GBD 2015 Mortality and Causes of Death Collaborators. Global, regional, and national life expectancy, all-cause mortality, and cause-specific mortality for 249 causes of death, 1980-2015: a systematic analysis for the Global Burden of Disease Study 2015. Lancet. 2016;388:1459-544.

59. Foo J, Landis S, Maskell J, et al. Continuing to confront COPD international patient survey: economic impact of COPD in 12 countries. PLOS ONE. 2016; 11(4):e0152618.

60. Alvarez-Moreno C, Cortes J, Denning D. Burden of fungal infections in Colombia. J Fungi. 2018;4(2):41.

61. Gugnani H, Denning D. Burden of serious fungal infections in the Dominican Republic. J Infect Public Health. 2016;9:7-12..

62. Chayakulkeeree M, Denning D. Serious fungal infections in Thailand. Eur J Clin Microbiol Infect Dis. 2017;36:931-5.

63. Mares M, Moroti-Constantinescu V, Denning D. The burden of fungal diseases in Romania. J Fungi. 2018;4:31..

64. Gamaletsou M, Drogari-Apiranthitou M, Denning D, et al. An estimate of the burden of serious fungal diseases in Greece. Eur J Clin Microbiol Infect Dis. 2016;35:1115-20.

65. Tiew PY, Ko FWS, Pang SL, et al. Environmental fungal sensitisation associates with poorer clinical outcomes in COPD. Eur Respir J. 2020;56(2): 2000418. https://doi.org/10.1183/13993003.00418-2020.

\section{Publisher's Note}

Springer Nature remains neutral with regard to jurisdictional claims in published maps and institutional affiliations.

Ready to submit your research? Choose BMC and benefit from:

- fast, convenient online submission

- thorough peer review by experienced researchers in your field

- rapid publication on acceptance

- support for research data, including large and complex data types

- gold Open Access which fosters wider collaboration and increased citations

- maximum visibility for your research: over $100 \mathrm{M}$ website views per year

At $\mathrm{BMC}$, research is always in progress.

Learn more biomedcentral.com/submissions 